\title{
Avaliação do desempenho e bem-estar de bezerros leiteiros em diferentes instalações consumindo diferentes fontes de volumoso
}

\author{
Evaluation of dairy calves performance and welfare kept on different facilities and consuming \\ different sources of roughage
}

Evaluación del rendimiento y bienestar de los terneros lecheros en diferentes instalaciones que consumen diferentes fuentes de forraje

\section{Resumo}

O objetivo foi avaliar o bem-estar de bezerros leiteiros alojados em confinamento ou em abrigos individuais, recebendo feno de alfafa ou silagem de sorgo. Foram utilizados oito animais, sendo quatro da raça Holandesa e quatro mestiços, dentre os quais seis eram machos e duas fêmeas, distribuídos aleatoriamente pela ordem de nascimento e chegada aos seguintes tratamentos: $\mathrm{AF}$ - abrigos individuais + feno de alfafa, $\mathrm{AS}$ - abrigos individuais + silagem de sorgo, $\mathrm{BF}$ - bezerreira convencional + feno de alfafa e BS - bezerreira convencional + silagem de sorgo. Os bezerros dos diferentes tratamentos não diferiram quanto ao tempo das atividades ócio, ruminação, idas aos cochos de volumoso e concentrado e mamando. Houve diferença significativa quanto a idas ao bebedouro, onde os animais mantidos no tratamento AS foram mais vezes ao bebedouro quando comparados com os dos demais tratamentos. A frequência respiratória dos bezerros mantidos no tratamento $\mathrm{AF}$ foi maior quando comparado com aos dos tratamentos BF e BS, porém não foi observada diferença quando comparado aos do tratamento AS. As instalações e fonte de volumoso não interferem no comportamento ingestivo de bezerros. Animais recém-instalados permanecem mais tempo em ócio em pé e menos tempo em atividade de ruminação. Bezerros leiteiros mantidos em abrigos individuais intensificam processos de perda de calor, como alteração da frequência respiratória.

Palavras-chave: Abrigo individual; Comportamento animal; Feno de alfafa; Frequência respiratória; Silagem de sorgo.

\footnotetext{
Abstract

The study had as objective evaluate dairy calves welfare housed in different facilities, kept confined or in individual hutches, receiving alfalfa hay or sorghum silage, as roughage. Eight animals were used, being four Holsteins and four crossbreed, which six were males and two were females, randomly distributed by birth order and arrival to the following treatments: AF - individual hatches + alfalfa hay; AS - individual hatches + sorghum silage; $\mathrm{BF}$ conventional calf housing + alfalfa hay; BS - conventional calf housing + sorghum silage. Calves from different treatments had similar behavior spending time with activities as idle, rumination, visits to troughs of concentrate and roughage and sucking. Animals kept in AS treatment were more often the water cooler when compared to animals of other treatments. The respiratory frequency of calves from $\mathrm{AF}$ treatment was higher when compared to animals from BF and BS treatments; however this difference wasn't observed when it was compared to animals from AS treatment. The facilities and roughage source doesn't interfere with feeding behavior. Newly installed animals remain more time in idleness standing and less time with rumination. Dairy calves kept in individual hatches enhance heat loss as the increase of respiratory frequency.
} 
Keywords: Individual hatches; Animal behavior; Alfafa hay; Respiratory frequency; Sorghum silage.

\section{Resumen}

El objetivo fue evaluar el bienestar de los terneros lecheros alojados em confinamiento o em refúgios individuales, recibiendo heno de alfafa o ensilado de sorgo. Se utilizaron ocho animales, cuatro de lar aza Holstein y cuatro mestizo, entre los cuales seis eran machos y dos hembras, distribuídos aleatoriamente por orden de nacimiento y llegada em los siguientes tratamentos: AF - refúgios individuales + heno de alfalfa, AS - refúgios individuales + ensilaje de sorgo, $\mathrm{BF}$ - becerro convencional + heno de alfalfa y BS - becerro convencional + ensilado de sorgo. Los terneros de los diferentes tratamentos no difirieron en tiempo libre, rumia, viajes a comederos de voluminosos y de concentrado y de lactancia. Hubo uma diferencia significativa con respecto a los viajes a la fuente de agua potable, donde los animales mantenidos em el tratamiento de AS fueron más a menudo a la fuente de agua potable em comparacion com los de los otros tratamientos. La frequencia respiratoria de los terneros mantenidos em el tratamiento de FA fue mayor em comparación com los de los tratamientos BF y BS, sin embargo, no hubo diferencia en comparación com los del tratamiento AS. Las instalaciones y la fuente de forraje no interfieren com el comportamiento de ingestión de los terneros. Los animales recién instalados pasan más tiempo em reposo y menos tiempo em actividad de rumia. Los terneros lecheros mantenidos em refugios individuales intensifican los procesos de pérdida de calor, como cambio em la frecuencia respiratoria.

Palabras clave: Refugio individual; Comportamiento animal; Heno de alfalfa; Frecuencia respiratoria; Ensilage de sorgo.

\section{Introdução}

A fase de cria de bovinos leiteiros deve contar com manejo eficiente para que os resultados esperados de produção no animal adulto e, consequentemente, lucratividade da propriedade sejam atingidos. Sabe-se que nesta fase é possível garantir este manejo utilizando-se instalações simples, porém investindo-se em conforto térmico, higiene, saúde e manejo nutricional de qualidade. Daí a necessidade de instalações adaptadas, com características construtivas que garantam o máximo de conforto e que permitam ao animal abrigado desenvolver todo seu potencial genético (Nääs \& Silva, 1998).

Costa e Silva (2011) desenvolveram um manual de boas práticas na criação de bezerros leiteiros, visando divulgar novos conceitos na criação desta categoria. Dentre os pontos que destacam em sua publicação, os autores revelam que a qualidade das instalações e da nutrição podem promover melhorias no desempenho animal, diminuição de enfermidades e melhoria na qualidade de vida dos bezerros, revertendo-se em lucro para o produtor. Suleiman (2012) comenta que, até os 60 dias de vida, deve-se realizar manejo adequado dos bezerros leiteiros, em especial das futuras matrizes leiteiras, considerando esta uma etapa fundamental do sistema de produção leiteira.

Algumas normativas, tendo como objetivo assegurar o bem-estar animal, foram desenvolvidas, resultando em mudanças na conduta dos profissionais a campo, tendo como exemplo as normativas internacionais da Vapnek e Chapman (2010), OIE (2019), bem como as brasileiras, como a Portaria $n^{\circ}$ 524/2011 (Brasil 2011) e IN 56/2008 (Brasil, 2008). Oriel \& Aloísio (2004) salientam que a eficiência da instalação está diretamente relacionada com a qualidade do ambiente e o grau de conforto que ela pode proporcionar aos animais, além da praticidade e baixo custo. Conforto significa acesso à água e a alimentos de qualidade, ambiente seco e controle de ecto e endoparasitas e de temperatura (Coelho, 2009).

Os estudos de bem-estar animal estão amparados em medidas específicas que determinam de forma científica o bemestar animal e as condições individuais de adaptação às condições ambientais impostas, sendo baseados em indicadores de cunho fisiológico, comportamentais e de produção. Sendo assim, o estudo teve por objetivo avaliar o bem-estar de bezerros leiteiros alojados em distintas instalações e com diferentes fontes de volumoso.

\section{Metodologia}

O estudo foi conduzido no período de maio a agosto de 2015, no Laboratório de Extensão, Pesquisa e Produção de Bovinocultura de Leite do Instituto Federal de Educação, Ciência e Tecnologia Farroupilha - Campus Alegrete, no município de Alegrete - RS. O município está situado em uma região com clima classificado por KOPPEN como Cfa, subtropical úmido, 
sem estação seca e com temperaturas médias variando de $14,3^{\circ} \mathrm{C}$ no inverno a $26,3^{\circ} \mathrm{C}$ no verão, com uma média de precipitações anuais de $1400 \mathrm{~mm}$ (Souto, 1984; Suertegaray, 1998).

Foram utilizados oito animais leiteiros, sendo quatro da raça Holandesa e quatro mestiços (Holandês x Jersey), dentre os quais seis eram machos e dois eram fêmeas. O período experimental teve duração de 90 dias. Após o nascimento, foi realizada a desinfecção do umbigo com solução de iodo à $7 \%$ e os bezerros permaneceram, aproximadamente, 12 horas com a mãe para a ingestão do colostro. Após, foram distribuídos aleatoriamente pela ordem de nascimento e chegada aos seguintes tratamentos:

$\mathrm{AF}$ - animais criados em abrigos individuais (casinhas) ao ar livre alimentados com dieta láctea e suplementados com feno de alfafa e concentrado;

AS - animais criados em abrigos individuais (casinhas) ao ar livre alimentados com dieta láctea e suplementados com silagem de sorgo e concentrado.

BF - animais criados em bezerreira (confinados) alimentados com dieta láctea e suplementados com feno de alfafa e concentrado;

BS - animais criados em bezerreira (confinados) alimentados com dieta láctea e suplementados com silagem de sorgo e concentrado;

Os animais foram mantidos em abrigos individuais cobertos, com $1 \mathrm{~m}^{2}$ de área útil, distribuídos em um piquete, com base forrageira de campo nativo. Aqueles que permaneceram confinados ficaram alojados em baias individuais (bezerreiras), com piso de concreto, cama de casca de arroz, paredes de alvenaria e coberto por telhas de amianto.

Todos os animais, independente do alojamento, receberam quatro litros de colostro fracionados em duas porções diárias até o sétimo dia. Do oitavo ao décimo quarto dia receberam leite, no total de quatro litros diários, fracionados em duas porções diárias. O leite era fornecido sempre após as ordenhas em mamadeiras de plástico de dois litros, assim as frações foram fornecidas às $9 \mathrm{~h}$ e $16 \mathrm{~h}$.

Aos quatorze dias foi introduzida a dieta sólida, composta por silagem de sorgo ou feno de alfafa conforme o tratamento, além de concentrado. O concentrado era farelado e possuía a mesma composição para todos os tratamentos (55\% de farelo de milho, $45 \%$ de farelo de soja e 5\% de mistura mineral), apresentando aproximadamente proteína bruta (PB) e NDT (NRC, 2000). A água era fornecida ad libitum em cochos individuais. As dietas eram ofertadas em duas frações diárias, sendo estas às $8 \mathrm{~h}$ e às $13 \mathrm{~h}$.

Para análise do desempenho animal, realizaram-se as avaliações de peso de vivo (PV), escore de condição corporal e consumos e conversão alimentar. As pesagens foram realizadas ao primeiro, $30^{\circ}$ e aos $60^{\circ}$ dias de permanência no alojamento e tratos experimentais, em balança eletrônica, precedido por um período de jejum de 12 horas. As avaliações de ganho de peso médio diário foram realizadas calculando-se o ganho de peso no período, dividido pelos dias entre as pesagens. A avaliação do escore de condição corporal foi realizado segundo metodologia proposta por Wildman et al. (1982), desenvolvida por Edmonson et al. (1989). Baseou-se em avaliações visuais e táteis das reservas corporais, por ocasião das pesagens, sendo utilizada a escala de 1 a 5 pontos, onde 1 equivale a animais muito magros, 2 animais magros, 3 classifica-se com animais em ECC intermediário, 4 animais gordos e 5 animais muito gordos. Para determinação do consumo total de matéria seca, foram feitas anotações diárias da quantidade de ração fornecida e das sobras, para cada animal. A determinação do percentual de umidade do feno de alfafa, silagem de sorgo e do concentrado foi realizando-se previamente a pré-secagem das amostras de volumosos, em estufa ventilada à $55^{\circ} \mathrm{C}$ por 72 horas, moídas em moinho tipo Willey, com peneira de crivos de $1 \mathrm{~mm}$. Para obtenção da matéria seca (MS) realizou-se secagem em estufa a $105^{\circ} \mathrm{C}$, durante 8 horas. A conversão alimentar foi calculada através do consumo diário do animal dividindo-se pelo ganho médio diário dos animais (kg de MS/kg de PV). 
Para obtenção dos dados de comportamento ingestivo, realizou-se a observação do comportamento diurno (12 horas por dia), perfazendo um total de 24 horas de observação, realizada aos 30 e aos 60 dias de permanência de cada bezerro no alojamento e tratos experimentais. Para obtenção do comportamento ingestivo, os dados foram coletados a cada dez minutos, sendo os comportamentos observados, os tempos de ócio em pé, ócio deitado, ruminando em pé, ruminando deitado, idas ao cocho do volumoso, concentrado e bebedouro, além do tempo mamando.

Para mensuração do bem-estar animal, foram analisadas, a cada hora do período de observação comportamental, variáveis fisiológicas, sendo elas: temperatura de pelame, através de um termômetro de infravermelho; temperatura retal, obtida com termômetro clínico, introduzido na ampola retal, por 3 minutos; frequência respiratória, medida através da contagem dos movimentos dos flancos dos animais, durante 15 segundos; e variáveis de qualidade sanitária, sendo avaliados: escores de higiene das patas e das pernas, classificadas através de escores visuais de 1 a 4 , onde: $1=$ muito sujo; $2=$ sujo; 3=limpo; e 4=muito limpo (Adaptado de Reneau et al., 2005); e a ocorrência de diarreia, que foi observada diariamente.

O delineamento experimental foi o inteiramente casualizado, com arranjo fatorial $2 \times 2$ (duas instalações e duas dietas), num total de quatro tratamentos, contendo duas repetições cada. A unidade experimental foi o bezerro. Os dados foram testados quanto a sua normalidade e sofreram análise de variância através do teste F, utilizando-se como covariável o sexo dos animais. As médias foram comparadas através do teste " $\mathrm{t}$ " de Student, com 5\% de significância.

\section{Resultados e Discussão}

Não houve diferença entre as fontes de volumoso e tipos de alojamento para consumo de volumoso, de concentrado e consumo total de MS ( $>>0,05$; Tabela 1). Em relação aos consumos, verificou-se média de 0,208 $\mathrm{kg}$ para consumo de volumoso; 0,248 kg para consumo de concentrado; e 0,457 kg para o consumo total de alimento. Bush (1991) comparou diversas fontes de volumosos para bezerros antes e após o desaleitamento e observou que o consumo voluntário de forragens por bezerros jovens é muito baixo, também demonstrou que bezerros consomem quantidades expressivas de forragem somente após alcançarem o máximo consumo de concentrado.

Maior consumo de matéria seca de forragem em bezerros foi observado para mistura de silagem com feno de alfafa, quando comparados ao fornecimento de silagem ou feno individualmente (Bush 1991). Essas diferenças de consumo podem ter relação com a qualidade e composição química das dietas, sendo esses fatores limitantes de consumo. A utilização de feno em dietas para bezerros lactentes, nem sempre proporciona melhora no consumo de alimentos sólidos e no desempenho dos animais. Oliveira et al. (2013) também não verificaram influência do fornecimento de feno de alfafa sobre o desenvolvimento corporal de bezerros lactentes da raça Girolando, desmamados aos 90 dias. Já o uso da silagem de sorgo para alimentação de bezerros não é tão reportado na literatura. Quigley (1985) verificou que para bezerros lactentes o consumo de feno só apresenta valores elevados após as seis semanas de idade, quando a ruminação se torna expressiva e o fluxo de tamponantes salivares é mais constante.

O uso de fontes de fibra na dieta de bezerros lactentes continua sendo um assunto que causa dúvida entre os produtores e, cada vez mais, um maior número de criadores têm optado por não fornecer volumosos para animais até 60 ou 90 dias de idade devido a baixo consumo, tendo em vista que o desenvolvimento do epitélio ruminal está diretamente relacionado com a ingestão de alimentos ricos em carboidratos não estruturais (Bernardes et al. 2007). Por outro lado, a fermentação de volumosos leva à maior concentração de acetato, considerado um ácido graxo de menor importância no que diz respeito ao desenvolvimento do rúmen (Bittar et al. 2007). 
Tabela 1. Consumo de volumoso, de concentrado e de consumo total de matéria seca $(\mathrm{kg})$ e peso corporal inicial, aos 30 e 60 dias de alojamentos e tratos experimentais de bezerros leiteiros.

\begin{tabular}{lccccc}
\hline \multirow{2}{*}{ Variável } & \multicolumn{4}{c}{ Tratamento } & \multirow{2}{*}{ P > F } \\
\cline { 2 - 5 } & AF & AS & BF & BS & \\
\hline Consumo de volumoso, kg & 0,317 & 0,174 & 0,207 & 0,134 & 0,3637 \\
Consumo de concentrado, kg & 0,257 & 0,262 & 0,149 & 0,325 & 0,4691 \\
Consumo total, kg & 0,574 & 0,437 & 0,356 & 0,460 & 0,6922 \\
Peso inicial, kg & 31,50 & 33,25 & 31,00 & 34,50 & 0,9000 \\
Peso aos 30 dias, kg & 45,45 & 47,25 & 46,00 & 50,00 & 0,9541 \\
Peso aos 60 dias, kg & 60,25 & 65,25 & 61,00 & 66,75 & 0,9199 \\
\hline
\end{tabular}

Médias com letras diferentes na linha apresentam diferença estatística pelo teste "t" de Student (5\% de significância). AF = Animais mantidos em abrigos individuais e alimentados com feno de alfafa; AS = Animais mantidos em abrigos individuais e alimentados com silagem de sorgo; $\mathrm{BF}=$ Animais mantidos em bezerreira coletiva e alimentados com feno de alfafa; $\mathrm{BS}=$ Animais mantidos em bezerreira coletiva e alimentados com silagem de sorgo.

Fonte: Autores.

Quando avaliado o peso dos animais em relação aos tratamentos avaliados, observa-se que não houve diferença estatística (P>0,05; Tabela 1) para os pesos inicial, aos 30 e aos 60 dias, apresentando média de 32,56 kg; 47,17 kg e 63,31 kg, respectivamente. Da mesma maneira, não foi observada diferença no ganho de peso médio diário dos bezerros ( $\mathrm{P}>0,05$; Tabela 2). Neste mesmo sentido, apesar do ganho de peso não ter diferido entre os tratamentos experimentais (média de $0,459 \mathrm{~kg} / \mathrm{dia}$ entre 0 e 30 dias; e média de $0,518 \mathrm{~kg} /$ dia entre 30 e 60 dias), houve incremento na capacidade de ganho de peso ao longo do período experimental.

Em pesquisa onde avaliou o consumo e ganho de peso de bezerros desaleitados aos trinta dias de idade que receberam dietas com ou sem a participação de feno de tifton, Coelho et al. (1999) encontrou valores semelhantes aos observados nos sistemas avaliados nesta pesquisa para consumo de feno e ganho de peso de bezerras aos 30 dias, em média $0,271 \mathrm{~kg}$ e 0,235 $\mathrm{kg}$, respectivamente. E consideraram estes consumos suficientes para suprir as necessidades dos bezerros, uma vez que antes das oito semanas de vida destes animais, o consumo de forragem é muito baixo, o desperdício é elevado e os requerimentos dos animais poderiam ser atendidos somente com o fornecimento de leite e concentrado. Em seu estudo Plaza et al. (1990) demonstram que o fornecimento do feno separado do concentrado pode ser uma das razões para o seu baixo consumo pelos bezerros. Da mesma maneira Castro e Zanetti (1998) verificaram consumos de matéria seca superiores para bezerros que receberam feno picado, incorporado ao concentrado quando comparados àqueles que receberam somente concentrado. A literatura é escassa em informações sobre as exigências nutricionais de bezerros jovens, principalmente na fase de aleitamento, o NRC (2001) não faz distinções entre bezerros machos e fêmeas, pois as diferenças são negligenciáveis até $100 \mathrm{~kg}$ de peso corporal. 
Tabela 2. Escore de condição corporal (ECC) inicial, aos 30 e 60 dias, ganhos de peso médio diário (GMD) do inícios aos 30 dias e dos 30 aos 60 dias, de bezerros nos diferentes instalações e diferentes fontes de volumosos.

\begin{tabular}{lccccc}
\hline \multirow{2}{*}{ Variável } & \multicolumn{4}{c}{ Tratamento } & \multirow{2}{*}{$\mathrm{P}>\mathrm{F}$} \\
\cline { 2 - 5 } & $\mathrm{AF}$ & $\mathrm{AS}$ & $\mathrm{BF}$ & $\mathrm{BS}$ & \\
\hline ECC inicial, pontos & 2,00 & 2,05 & 1,85 & 2,15 & 0,8141 \\
ECC aos 30 dias, pontos & 2,25 & 2,15 & 2,15 & 2,40 & 0,7164 \\
ECC aos 60 dias, pontos & 2,25 & 2,35 & 2,25 & 2,50 & 0,8264 \\
GMD do início aos 30 dias, kg/dia & 0,442 & 0,450 & 0,462 & 0,484 & 0,9866 \\
GMD dos 30 aos 60 dias, kg/dia & 0,469 & 0,590 & 0,474 & 0,540 & 0,7411 \\
\hline
\end{tabular}

Médias com letras diferentes na linha apresentam diferença estatística pelo teste "t" de Student (5\% de significância). AF $=$ Animais mantidos em abrigos individuais e alimentados com feno de alfafa; AS = Animais mantidos em abrigos individuais e alimentados com silagem de sorgo; $\mathrm{BF}=$ Animais mantidos em bezerreira coletiva e alimentados com feno de alfafa; $\mathrm{BS}=$ Animais mantidos em bezerreira coletiva e alimentados com silagem de sorgo.

Fonte: Autores.

O escore de e condição corporal dos bezerros foi avaliado no nascimento (média de 2,01 pontos), aos 30 (média de 2,24 pontos) e aos 60 dias (média de 2,34 pontos) e não apresentou diferença entre os tratamentos ( $\mathrm{P}>0,05$; Tabela 2), no entanto observa-se que numericamente houve aumento gradativo do escore de condição corporal à medida que os animais permaneceram no experimento, o que pode estar relacionado ao fato do acompanhamento da elevação do peso corporal destes animais. A evolução do escore de condição corporal dos animais é um fator importante porque o mesmo contribui para a tomada de decisões sobre medidas de impacto na produção, sendo possível ajustar épocas de desmamar as crias ou definir quando e quanto suplementar a dieta de matrizes, porém o escore de condição corporal é mais útil na predição do desempenho reprodutivo dos animais.

Independentemente de fontes de volumoso e instalações, os bezerros apresentaram ao longo do período experimental, em média 0,490 kg de ganho de peso médio diário. Estes valores são superiores aos reportados por Campos et al. (1992), tanto para animais criados em bezerreiros (0,362 kg/dia), quanto em abrigos individuais $(0,292 \mathrm{~kg} / \mathrm{dia})$. Madril et al. (2015) verificou que animais alimentados com feno aos 60 dias proporcionaram ganho de peso de 16,50 4,268 kg, sendo superior aos que não receberam feno em sua dieta. No presente estudo, os animais tiveram média de ganhos de peso de 30,75 kg durante todo o período experimental, do $1^{\circ}$ aos 60 dias.

Na Tabela 3 são apresentados os dados de porcentagem das atividades ócio, ruminação, idas aos cochos de volumoso e concentrados e mamando. Verifica-se que não houve diferença estatística $(\mathrm{P}>0,05)$ entre os tratamentos para as atividades de ócio em pé (média de 28,43\%), ócio deitado (média de 38,93\%), ruminando deitado (média de 15,62\%), ruminando em pé (média de 11,24\%), presença nos cochos de volumoso (média de 6,57\%) e de concentrado (média de 4,52\%). No entanto, ao se analisar as idas ao bebedouro, verifica-se que os animais que permaneceram no tratamento AS compareceram percentualmente mais vezes $(2,73 \%)$ ao bebedouro quando comparado com os demais tratamentos (média de 1,36\%). 
Tabela 3. Porcentagem de tempo em horas das atividades de ócio em pé, ócio deitado, ruminando em pé, ruminando deitado, idas ao cocho de volumoso, concentrado e bebedouro e tempo mamando dos bezerros leiteiros mantidos em diferentes instalações sob diferentes fontes de volumoso.

\begin{tabular}{|c|c|c|c|c|c|}
\hline \multirow{2}{*}{ Variável } & \multicolumn{4}{|c|}{ Tratamento } & \multirow{2}{*}{$\mathrm{P}>\mathrm{F}$} \\
\hline & $\mathrm{AF}$ & AS & $\mathrm{BF}$ & $\mathrm{BS}$ & \\
\hline Ócio em pé, \% & 26,98 & 33,47 & 25,61 & 27,66 & 0,6028 \\
\hline Ócio deitado, \% & 46,45 & 37,91 & 37,22 & 34,15 & 0,1107 \\
\hline Ruminando deitado, $\%$ & 11,27 & 11,61 & 19,81 & 19,81 & 0,3730 \\
\hline Ruminando em pé, \% & 2,04 & 4,43 & 2,73 & 2,04 & 0,3121 \\
\hline Cocho volumoso, $\%$ & 5,46 & 4,44 & 7,85 & 8,53 & 0,4326 \\
\hline Cocho concentrado, $\%$ & 4,10 & 4,78 & 3,75 & 5,46 & 0,6436 \\
\hline Mamando, \% & 2,73 & 2,40 & 2,73 & 2,73 & 0,4262 \\
\hline Bebedouro, \% & $1,36 \mathrm{~b}$ & $2,73 a$ & $1,36 b$ & $1,36 \mathrm{~b}$ & $<0,0001$ \\
\hline
\end{tabular}

Médias com letras diferentes na linha apresentam diferença estatística pelo teste " $t$ " de Student ( $5 \%$ de significância). AF $=$ Animais mantidos em abrigos individuais e alimentados com feno de alfafa; $\mathrm{AS}=$ Animais mantidos em abrigos individuais e alimentados com silagem de sorgo; $\mathrm{BF}=$ Animais mantidos em bezerreira coletiva e alimentados com feno de alfafa; $\mathrm{BS}=$ Animais mantidos em bezerreira coletiva e alimentados com silagem de sorgo.

Fonte: Autores.

Bica (2005) comenta que são vários os fatores que influenciam os animais quanto à preferência pelo bebedouro no momento da ingestão de água. Quando analisada as médias das temperaturas diárias dos períodos de observação comportamental, percebe-se que a temperatura média diária (Tabela 5) dos dias de observação dos animais do tratamento AS foi superior ao demais dias, tendo como média de temperatura $20,96^{\circ} \mathrm{C}$ o que pode justificar a maior ingestão de água desses animais. Façanha et. al (1997) verificaram que bezerros mantidos em abrigos móveis ao ar livre ingeriram água mais vezes por dia do que aqueles mantidos em galpões, ao avaliarem o comportamento de bezerros da raça Holandesa submetidos a diferentes tipos de instalações.

Os resultados obtidos nos dois períodos de observação comportamental diferiram entre si quanto ao percentual de horas despendidas nas atividades de atividades de ócio em pé e ruminação deitado (Tabela 4). Os bezerros permaneceram mais tempo em ócio em pé no primeiro período (32,78\%) que animais no segundo período (24,07\%). Enquanto que para a atividade ruminando deitado, observou-se que os animais nos primeiros 30 dias permaneceram menos tempo nesta atividade (10,24\%) do que nos últimos 30 dias de experimentação, segundo período de avaliação, apresentando média de $26 \%$. Este resultado pode estar relacionado ao aumento da quantidade de alimento ingerido. Apesar de não ter havido diferença estatística para a permanência aos cochos, tanto de volumoso quanto de concentrado, nota-se que os animais no segundo período permaneceram $3 \%$ a mais de tempo no cocho de volumoso. O maior consumo de volumoso implica em maior consumo de fibra pelos animais, o que consequentemente exige maior tempo de ruminação para que ocorra a digestão do alimento consumido. No entanto, quando avaliado o percentual de participação das atividades de ócio deitado, ruminando em pé, permanência nos cochos de volumoso e concentrado, bem como mamando e bebendo, nota-se que não houve diferença estatística, apresentado média de $38,93 \%, 2,91 \%, 6,57 \%, 4,52 \%, 2,64 \%$ e $1,70 \%$, respectivamente ( $>0,05$; Tabela 4). 
Tabela 4. Porcentagem de tempo em horas das atividades de ócio em pé, ócio deitado, ruminando deitado, ruminando em pé, idas ao cocho de volumoso, idas ao cocho de concentrado, tempo mamando e idas ao bebedouro dos bezerros leiteiros avaliados em dois períodos de observação comportamental.

\begin{tabular}{lccc}
\hline \multicolumn{1}{c}{ Variável } & \multicolumn{2}{c}{ Período de experimental } & \multirow{2}{*}{ P $>\mathrm{F}$} \\
\cline { 2 - 4 } & 30 dias & 60 dias & 0,0310 \\
\hline Ócio em pé, \% & $32,78 \mathrm{a}$ & $24,07 \mathrm{~b}$ & 0,1576 \\
Ócio deitado, \% & 41,66 & 36,20 & 0,0130 \\
Ruminando deitado, \% & $10,24 \mathrm{~b}$ & $21,00 \mathrm{a}$ & 0,4706 \\
Ruminando em pé, \% & 2,50 & 3,31 & 0,1419 \\
Cocho volumoso, \% & 5,12 & 8,02 & 0,8654 \\
Cocho concentrado, \% & 4,61 & 4,43 & 0,3343 \\
Mamando, \% & 2,73 & 2,56 & 0,1778 \\
Bebedouro, \% & 1,36 & 2,04 & \\
\hline
\end{tabular}

Médias com letras diferentes na linha apresentam diferença estatística pelo teste “t” de Student (5\% de significância).

Fonte: Autores.

$\mathrm{Na}$ Tabela 5 são apresentadas as médias de escores de higiene de limpeza nas patas, de limpeza nas pernas, de temperaturas do dia, pelame e retal e frequência respiratória dos animais pertencentes aos tratamentos AF, AS, BF e BS. Não foi observada diferença $(\mathrm{P}>0,05)$ nas médias de escores de higiene de limpeza nas patas, média de 3,00 pontos, e pernas, média de 3,05 pontos. A ausência de diferença nas médias de higiene pode ser devido aos animais dos abrigos individuais não serem expostos a lugares sujos e não ter tido ocorrência de chuva nos períodos de avaliação, bem como os animais das bezerreiras eram mantidos em constante higiene, tendo a cama trocada sempre quando necessário, priorizando o bem-estar animal. Amaury et al. (2005) destacam que o sucesso no desenvolvimento de bezerros está na higiene e a desinfecção de baldes e instalações utilizados com os animais.

Observa-se, na Tabela 5, que para as médias para temperatura diária $\left({ }^{\circ} \mathrm{C}\right)$ houve diferença estatística entre os tratamentos. Os tratamentos $\mathrm{AS}$ e $\mathrm{BF}$ apresentaram as maiores médias de temperatura diárias $\left(20,96^{\circ} \mathrm{C}\right.$ e $\left.19,32^{\circ} \mathrm{C}\right)$, no entanto o tratamento BF não diferiu dos tratamentos que apresentaram as menores médias de temperatura durante as avaliações, sendo elas $17,31^{\circ} \mathrm{C}$ e $15,67^{\circ} \mathrm{C}$, respectivamente para os tratamentos AF e BS. Justificam-se essas médias pelas oscilações de temperatura no período experimental, pois cada observação era realizada de acordo com o tempo de permanência de cada bezerro nos tratamentos em dias distintos ocasionando diferentes temperaturas.

Em relação às temperaturas retal e de pelame dos animais nos tratamentos estudados, não foram observadas diferenças estatísticas $(\mathrm{P}>0,05)$, ficando com média de $38,56^{\circ} \mathrm{C}$ e $25,99^{\circ} \mathrm{C}$, respectivamente para temperatura retal e de pelame. De acordo com Campos (1985), a faixa ideal de temperatura retal para bezerros situa-se entre $38,0^{\circ} \mathrm{C}$ e $39,3^{\circ} \mathrm{C}$ e essa condição desejável foi encontrada em todos os tratamentos. Mesmo havendo diferença estatística na temperatura diária, percebe-se que essas diferenças ficaram em torno de $20,96^{\circ} \mathrm{C}$ e $15,67^{\circ} \mathrm{C}$, essa amplitude térmica pode ser considerada pequena, o que permitiu com que a temperatura de pelame variasse pouco $\left(24,96^{\circ} \mathrm{C}\right.$ a $\left.26,70^{\circ} \mathrm{C}\right)$. A temperatura de superfície corporal depende principalmente das condições ambientes de umidade, temperatura do ar e vento, e das condições fisiológicas, como vascularização e evaporação pelo suor (De Almeida et. al, 2005). 
Tabela 5. Médias dos escores de higiene nas patas, higiene nas pernas, temperaturas do dia, do pelame e retal e frequência respiratória dos bezerros leiteiros mantidos em diferentes instalações sob diferentes fontes de volumoso.

\begin{tabular}{lccccc}
\hline \multirow{2}{*}{ Variável } & \multicolumn{4}{c}{ Tratamento } & \multirow{2}{*}{$\mathrm{P}>\mathrm{F}$} \\
\cline { 2 - 5 } & $\mathrm{AF}$ & $\mathrm{AS}$ & $\mathrm{BF}$ & $\mathrm{BS}$ & \\
\hline Escore de higiene nas patas, pontos & 2,75 & 3,25 & 3,00 & 3,00 & 0,6445 \\
Escore de higiene nas pernas, pontos & 2,50 & 3,50 & 2,95 & 3,25 & 0,1899 \\
Temperatura do dia, ${ }^{\circ} \mathrm{C}$ & $17,31 \mathrm{~b}$ & $20,96 \mathrm{a}$ & $19,32 \mathrm{ab}$ & $15,67 \mathrm{~b}$ & $<0,0001$ \\
Temperatura de pelame, ${ }^{\circ} \mathrm{C}$ & 24,96 & 26,70 & 26,51 & 25,80 & 0,4172 \\
Temperatura retal, ${ }^{\circ} \mathrm{C}$ & 38,57 & 38,52 & 38,65 & 38,50 & 0,9252 \\
Frequência respiratória, mov./min & $43,69 \mathrm{a}$ & $41,53 \mathrm{ab}$ & $39,35 \mathrm{~b}$ & $33,04 \mathrm{~b}$ & 0,0002 \\
\hline
\end{tabular}

Médias com letras diferentes na linha apresentam diferença estatística pelo teste "t" de Student (5\% de significância). AF = Animais mantidos em abrigos individuais e alimentados com feno de alfafa; AS = Animais mantidos em abrigos individuais e alimentados com silagem de sorgo; $\mathrm{BF}=$ Animais mantidos em bezerreira coletiva e alimentados com feno de alfafa; $\mathrm{BS}=$ Animais mantidos em bezerreira coletiva e alimentados com silagem de sorgo.

Fonte: Autores.

A frequência respiratória (Tabela 5) dos bezerros mantidos no tratamento AF foi maior $(43,69$ mov./min; P<0,05) quando comparado com os animais dos tratamentos BF (39,35 mov./min) e BS (33,04 mov./min), porém essa diferença não pôde ser observada quando comparado com os animais do tratamento AS (41,53 mov./min), que também não diferiu dos demais tratamentos. Conforme estudo realizado por Cunha et. al (2005) animais mantidos em abrigos individuais ao ar livre intensificaram os processos latentes de perda de calor na tentativa de manter a temperatura corporal dentro da normalidade fisiológica. Esse mecanismo fisiológico promove a perda de calor por meio evaporativo (Façanha et. al, 2011), explicação a qual justifica que animais mantidos em abrigos individuais tenham apresentado maiores valores para esta variável.

\section{Conclusão}

Não há influência da utilização de diferentes fontes de volumosos (feno de alfafa ou silagem de sorgo) e diferentes instalações (bezerreira ou abrigos individuais) sobre o desempenho de bezerros leiteiros.

As instalações e a fonte de volumoso não interferem no comportamento ingestivo de bezerros leiteiros. Animais recém instalados permanecem mais tempo em ócio em pé e menos tempo em atividade de ruminação. A temperatura diária influencia na ingestão de água de bezerros leiteiros alojados em abrigos individuais.

Bezerros leiteiros mantidos em abrigos individuais intensificam processos de perda de calor como o aumento da frequência respiratória.

Independente da instalação, quando mantidos os aspectos higiênicos, não há diferença nos escores de higiene de patas e pernas.

\section{Agradecimentos}

Ao Instituto Federal Farroupilha - Campus Alegrete e ao Laboratório de Extensão, Pesquisa e Produção Bovinocultura de Leite pelo apoio para realização da pesquisa. 
Research, Society and Development, v. 10, n. 6, e33510615524, 2021

(CC BY 4.0) | ISSN 2525-3409 | DOI: http://dx.doi.org/10.33448/rsd-v10i6.15524

\section{Referências}

Amaury, A. O.; Hymerson, C. A.; \& Cristiano, B. M. (2005) Criação de Bezerras em Sistemas de Produção de Leite. EMBRAPA, Circular Técnica nº 38.

Brasil (2008) IN n 56 - Estabelece os procedimentos gerais de recomendações de boas práticas de bem-estar para animais de produção e de interesse econômico (Rebem), $\quad$ abrangendo $\quad$ os $\quad$ sistemas de $\quad$ produção http://www.agricultura.gov.br/arq_editor/file/Desenvolvimento_Sustentavel/Producao-Integrada-Peduaria/IN\%2056\%20de\%202009.pdf

Brasil (2011). Portaria n 524 - Institui a Comissão Técnica Permanente para estudos específicos sobre bem-estar animal nas diferentes áreas da cadeia pecuária. http://www.agricultura.gov.br/arq_editor/file/Desenvolvimento_Sustentavel/Producao-Integrada-Peduaria/Portaria\%20524\%20de\%202011.pdf

Bica, G. S. (2005) Bebedouros: bem-estar animal e proteção ambiental no suprimento de água para bovinos de corte. http://repositorio.ufsc.br/handle/123456789/102688

Coelho, S. G. (2009). Desafios na criação e saúde de bezerros. Ciência Animal Brasileira, 1, 01-16.

Campos, O. F. (1985). Criação de bezerros até a desmama. EMBRAPA.

Costa, M. J. R. P.; \& Silva, L. C. M. (2011). Boas práticas de manejo: bezerros leiteiros. FUNEP.

Cunha, D. N. F. V.; Campos, O. F.; Pereira, J. C. et al. (2007). Desempenho, variáveis fisiológicas e comportamento de bezerros mantidos em diferentes instalações: época chuvosa. Revista Brasileira de Zootecnia, 36(4), 1140-1146.

De Almeida, G. L. P.; Pandorfi, H., Guiselini, C., et al. (2010). Investimento em climatização na pré-ordenha de vacas girolando e seus efeitos na produção de leite. Revista Brasileira de Engenharia Agrícola e Ambiental, 14(12), 1337-1344.

Edmonson, A. J., Lean, I. J., Weaver, L. D., et al. (1989). A body condition scoring chart for Holstein dairy cows. Journal of Dairy Science, 72, 68-78.

Façanha, D, Vasconcelos, A, Olivio, C et al. (1997). Comportamento de bezerros da raça Holandesa submetidos a diferentes tipos de instalações. Reunião Anual da Sociedade Brasileira de Zootecnia, 23, 115-116.

Vapneck, J.; Chapman, M. S. (2010). Legislative and regulatory options for animal welfare, FAO Legislative Study, no. 104.

Nääs, I.. A.; Silva, I. J. O. (1998) Técnicas modernas para melhorar a produtividade dos suínos através do controle ambiental. Editorial de la U.N.L.P.

NRC Nutrient Requirement of Beef Cattle

OIE Organización Mundial de Sanidad Animal (2019). Código sanitario para los animales terrestres: consideraciones generales. http://www.oie.int/index.php?id=169\&L=2\&htmfile=sommaire.htm

Oriel, F. C.; \& Aloísio, T. C. (2004). Instalações para bezerros de rebanhos leiteiros. EMBRAPA, Circular Técnica n80.

Reneau, J. K., Seykora, A. J., Heins, B. J., et al. (2005). Association between hygiene scores and somatic cell scores in dairy cattle. Journal of American Veterinary Medical Association, 227, 1297-1301.

Souto, J. J. (1984). Deserto, uma ameaça? Secretaria da Agricultura, 1984.

Suertegaray, D. M. A. (1998). Deserto grande do sul: controvérsia. (2a ed.), Editora UFRGS.

Suleiman, K. (2012). Bezerras bem manejadas produzem mais. Revista A Lavoura, 693, 24-25.

Wildman, E. E., Jones, G. M., Wagner, P. E., et al. (1982). A dairy cow body condition system and its relationship to selected production characteristics. Journal of Dairy Science, 65, 495-501. 